\title{
Key Factors of Cognitive Performance in Moroccan Preschool: Evidence from Random Slope Model
}

\author{
Aomar IBOURK ${ }^{1}, \&$ Salah Eddine TAHA ${ }^{1}$ \\ ${ }^{1}$ Research Group of Social Economic (GRES), Faculty of Law Economics and Social Sciences, Cadi Ayyad \\ University, Marrakesh, Morocco \\ Correspondence: Salah Eddine TAHA, Research Group of Social Economic (GRES), Faculty of Law Economics \\ and Social Sciences, Cadi Ayyad University, Marrakesh, Morocco.
}

Received: September 8, 2018

doi:10.5539/ibr.v11n11p92

\author{
Accepted: October 11, $2018 \quad$ Online Published: October 16, 2018 \\ URL: https://doi.org/10.5539/ibr.v11n11p92
}

\begin{abstract}
Compared to social factors, some studies have concluded that the quality of school environment is not important for learning. However, other studies have pointed out the divergence from this finding, highlighting the importance of environmental and educators quality regarding cognitive acquisition. Therefore, this article is in the same vein, and this, by seeking in a Moroccan context to identify the factors likely to influence cognitive learning in early childhood. The major features of our research reveal that in the Moroccan context mothers' level of education, environment's quality, the training of educators and class size are among the key factors of preschool learning. Multilevel modeling is applied to data from an ad hoc survey of 780 children in 45 pre-schools.
\end{abstract}

Keywords: education (A20), environment's school (I250), microeconomics (B21), multilevel estimation (C13), skills (I250)

\section{Introduction}

Many researches have linked the quality of early education to the efficiency of educational systems and thus to the heterogeneity of cognitive acquisitions and the rate of failure at later levels. Morocco, as a signatory of international conventions including the Convention of the Rights of the Child, is committed to protecting children's rights to education, health, safety, equality, etc. Nevertheless, various reports that have touched the Moroccan preschool (CSE, UNESCO, World Bank, etc.) underlined the insufficiencies and the poor performances which singularize the early education. In fact, Moroccan children who arrive in the first year of primary education start their studies with different chances, in favor of those who have benefited from a preschool of quality, and therefore with unequal chances to succeed in their schooling. Also, because of limited capacity in public structures and the preponderance of the private sector, it is the law of the market that decides on the establishment of preschool structures (Global Education and Formation, 2014). Considering all these issues, it is clear that a fairly deep reflection is needed on the Moroccan preschool and the determinants of its quality.

We will present in this paper an overview of the literature relating to the determinants of school performance. Then, we briefly present the characteristics that mark the Moroccan preschool. Finally, we will expose the different results from our empirical study.

\section{The Family Environment as a Grid for Analyzing School Performance and Success}

Initially economists conceptualized the process of success as one of the aspects of family behavior theory (Becker and Tomes 1979). Moreover, they tried to consider the behavior of the family in terms of fertility, choice of the marital model, and investment in human capital as an integral part of the transmission of income and inequality models (Wolf and Haveman, 1995).

Indeed, Wolf and Haveman (1995) conceptualized the family as a production unit that uses real inputs to generate utility for its members. They also emphasize that parents make decisions regarding the generating of family economic resources (labor supply); they also determine the uses (consumption, asset accumulation, or investment in children) of theses resources. Parents also make a variety of other choices such as fertility, location, and family stability that both influence the returns on productive efforts and directly affect the well-being of 
members of the family. In addition, the amount of family resources allocated to children, the nature of these resources and the timing of the distribution of their resources greatly affect the success of children in their families. In this sense, Wolf and Haveman (1995) add the number of siblings, the type of neighborhood in which children grow up, the number of possible moves of the family and the structure of the family (traditional family $/$ single-parent family).

Having said that, Leibowitz (1974), Becker and Tomes (1979) and Wolf \& Haveman (1995) have all marked a point of convergence in relation to the importance of the genetic inheritance (human capital) transmissible from parents to children in the success of these children. In fact, children begin their lives with a genetic heritage transmitted by their natural parents, genetic inheritance is described by the "Markov process". On average, parents with fairly high levels of education will produce children who are likely to achieve high levels of schooling too, but not necessarily as much as their parents.

Although the debate about the factors that best explain success still prevails between researchers, their positions converge when it comes to culture and social origin as determinants of success and learning. Indeed, Bourdieu and Passeron (1964) support the existence of a close link between culture and social origin on one side, and the success of another. Moreover, they view school as a factor of social conservation rather than a factor of social mobility (theory of origin and social reproduction). In the same perception, Gras (1974) argues that social origin and culture can impact school success and performance as much as the intellectual dispositions and character of children. Baudelot and Establet (1971) are also in the same vein, concluding that the children of privileged classes are more successful in school compared to children from disadvantaged social classes.

All these arguments (culture and social origin) are somehow related. But it must be noted that such a school of thought has not been deprived of criticism. Moreover, the research carried out by Cherkaoui (1999) has led to the conclusion that, despite particularly difficult socio-economic conditions, some children from underprivileged backgrounds arrive through school to achieve upward social mobility. Also, Duru-Bellat (2003) questioned this ideology (systematic influence of culture and social origin on the success of children). According to the author, the most disadvantaged individuals in some education systems have higher educational achievement than other education systems.

\section{From the Differentiation of School Contexts to the Construction of Contextual Effect}

In order to have an analysis of the determinants of school performance, in this section we summarize a review of performance theories. We can generally subdivide the literature on the influence of the school environment into three theories, to wit: the school-effect theory, the teacher-effect, and the class-effect.

\subsection{The School-Effect}

Since the eighties, the sociology of education has begun to take an interest in the possible impact of schools on student performance, and this, apart from the specific characteristics of students and their families. Indeed, the school-effect principle states that schools can have their own effectiveness, regardless of the specificities of their audience. In other words, school is no longer seen as a monolithic system acting blindly in the same way everywhere and at the same time, but rather as the aggregation of multiple units each producing significantly different effects on educational outcomes (Cousin, 1993). This theory was built on the work of Beck and Murphy (1998), who have the merit of having tried to identify the specificities of so-called high-performance schools. Moreover, they pointed out that in well-performing schools, school results are analyzed in order to elaborate corrective reforms to the teaching provided, also the in-service training of the teaching staff and the contacts with the parents of the pupils are highly sought-after policies. In the same context, Grisay (2007) believes that in well-performing schools, teachers define and pursue clear objectives with students, courses are well structured and assessments help to regulate teaching. Consequently, these so-called high-performance schools can embody a good reputation allowing them to manage the competition and the parents' pressure.

Therefore, the school-effect theory explains the difference in performance between schools by a variety of variables specific to the school. Indeed, Meuret (2000) confirms that hierarchical, physical, pedagogical and managerial aspects are decisive in the acquisition of skills and academic performance. Characteristics that distinguish one school from another constitute a kind of internal environment that promotes learning and, consequently school performance. In this sense, the internal determinants likely to positively impact the performance of a school consist of an effective director, the support that the community brings to the school, a regular supervision, the endowment of a teaching device, and adequate quality infrastructure and materials (Meuret, 2000, Duru-Bellat, 2003). These conclusions were also confirmed by Bressoux (1995) and Coussin (1998), the work of the latter concluded that the family context, the school context and the school climate have a direct impact on student performance. 


\subsection{The Teacher-Effect}

The theoretical principle of the teacher-effect states that the performance of the children may vary from teacher to teacher. In this sense, the literature has been able to explain the variations in performance by the difference in teaching methods practiced, the difference in the levels of training, qualification and experience of teachers (Meuret, 2000, Duru-Bellat, 2003).

Indeed, Bressoux (2006) proceeded by a classification of teachers in two classes, to wit: effective teachers and those who are not. The author argues that ineffective teachers are likely to subject weak students (poor-performing students) to too much criticism and prefer to lighten and simplify learning objectives. In addition, teachers have less patience when they question them, criticize them regularly, interact less with them and ask them simpler questions. In total, teachers expose weak students to a poorer curriculum (Jarlégan, 2008). On the other hand, teachers who are qualified as effective, value their students and develop a constant attitude toward low scores by accepting, for example, that a student does not understand but he is not necessarily "weak" (Lautier et allieu, 2008). Also, a set of researchers defines effective teachers as those who have received adequate training and experience, are provided with teaching materials, prepare their courses and plan learning according to the time allotted to them, They organize individual work, class discussions, group work, question and answer sessions, provide explanations, and provide special guidance for students with learning difficulties (Duru-Bellat, 2003 ; Robin, 2009).

Finally, we find in the literature that pedagogical practices, differences in training and qualifications, judgments and differential expectations of teachers combine together to give birth to a master effect that intervenes in the cognitive performance of children.

\subsection{The Class-Effect}

The analysis of the differences in performance between classes in the same school led Hanushek (1971) to find that the results of school performance depended on the class to which the children belong. Thus, the sketches of the theory of the class-effect were able to arise. Indeed, this last one explains the differences of school performances by the different compositions of the classes. In this sense, Veldman and Brophy (1974) deduced that the level of performance is higher among classes that are composed mainly of children from wealthy families. While classes mostly made up of children from disadvantaged families have a lower success rate. This phenomenon can have consequences for the image that children have of themselves. Indeed, convinced of belonging to a class deemed weak, children will reduce their involvement and their efforts in learning. As a result, poor self-image leads to poor outcomes through a process of disinvestment of children.

However, other researchers have investigated the impact of the degree of homogeneity on school performance. With this in mind, Robin (2009) and before him Kerckoff (1986) both emphasized that performance increases as the initial grade level of the classroom is better. They also concluded that classes where groups of apprentices are homogeneous further increase performance gaps between students, as bright students progress better by belonging to homogeneous classes compared to children in heterogeneous classes. Moreover, belonging to heterogeneous classes is more likely to be perceived as an advantage for students whose performance level is below average, unlike students whose performance level is above average (Mingat, 1984). Nevertheless, Duru-Bellat and Mingat (1997) have quantified the magnitude of the advantages and disadvantages by confirming that the gains of "weak" students from heterogeneous classes far outweigh the losses of bright students in a heterogeneous context.

\section{Preschool Education in Morocco}

Pre-school education in Morocco is a sector whose main concern is the care of early childhood education, often the age of these children varies from 3 to 5 years. The first of the singularities that mark this sector in general is the multitude of supervisory bodies and the heterogeneity of the frames of reference that define the orientations and objectives of pre-school education. Indeed, the preschool sector in Morocco is characterized by different bodies of guardianship namely, the Ministry of National Education, the Ministry of Youth and Sports, the Ministry of Habous and Islamic Affairs and National Mutual Aid. This segmentation, which reflects several stakeholders and several types of institution, explains the diversity and the heterogeneity of the content, practices and languages of instruction.

The second characteristic of preschool education in Morocco is the fact that a very large proportion of preschool establishments belong to the private sector, and this, in parallel with classes integrated into so-called public establishments, which are always trying to improve their rates capacity, but the workforce remains very small compared to those supported in the private sector. In addition, Moroccan preschool dependence on the private 
sector over the last twenty years has led to a limited, unfair and dependent quality of pre-school education for families with sufficient resources (El Andaloussi \& Faiq) ${ }^{1}$. Also, pre-school education in Morocco is not yet able to overcome the challenge of widespread access to preschool. Moreover, given the small evolution of the numbers benefiting from the educational care, we can conclude that it is impossible to reach this objective in the short term.

- the number of children enrolled in the preschool cycle

\section{Source: done by the author}

In fact, the overflight of the number of preschool children advanced by the Ministry of National Education in Morocco has led us to note that in general, the preschool sector has not made any progress in quantitative terms since 1999 until 2016. All in all, although all the protagonists of preschool mark a point of convergence, and this, by stipulating that the early childhood education is the key to the establishment of quality education in Morocco and the lever of his development. However, many problems persist or worsen. Indeed, the first challenge that continues to hamper the development of educational care is the expansion of access to pre-school education, the Moroccan preschool has not made progress in quantitative terms. The second challenge facing the Moroccan pre-school is the quality of education and the preschool environment which remains limited, inequitable and dependent on the private sector. The problem of the quality of preschool education is also illustrated by the heterogeneity of acquisition levels at the beginning of the primary cycle and the high rates of wastage and failure at later levels. Considering all these issues, it is clear that a fairly deep reflection is needed on the Moroccan preschool and the determinants of its quality.

\section{Methodology and Results}

\subsection{Methodology}

During this survey, children had to pass cognitive tests ${ }^{2}$ that touched four cognitive dimensions, to wit: Mathematics, Sensori-Motricity, Classical Arabic and French. These tests were used to evaluate the cognitive performance acquired at the end of the preschool cycle and with which preschooled children are supposed to start their primary cycle (calculation, vocabulary and comparison of quantities, colors and senses). Questionnaires were administered to the teachers and to the parents. We also collected information on environmental quality using the Early Childhood Environmental Rating Scale (ECERS) ${ }^{3}$. Note that the score obtained from the quality of the preschool environment consists of three modalities, to wit: "Inadequate Quality", "Minimum Quality" and "Good Quality".

The selection of children in the final year of the preschool cycle was done by a stratified two-stage sampling procedure. As for the stratification variables, the sample is stratified by the geographic area (urban / rural) and the status (private / public type) of the school. That said, the principle is to consider a set of randomly selected schools in each stratum based on the number of children at the end of the preschool year. If the chosen school has several classes of children in the final year of the preschool cycle, one of these classes drawn at random in each school. We proceed then by the standard explanation of the course of the tests, and this, while respecting the fixed durations of each test. In case the number of children in a class is less than 6 , we draw another class in the school, if necessary, the school is replaced by its replacement from the list.

The data used in this analysis concern exactly 784 children distributed in 45 schools. This data comes essentially from the information already collected from the forms and questionnaires administered to institutions and families of preschool children, and information extracted from the cognitive tests that children have spent in order to assess their cognitive knowledge at the end of the preschool cycle.

The data from this survey realized during the year of 2016, although rich in information, presents some difficulties related to the missing values that can skew the estimates. To overcome this difficulty, Rubin (1987) introduced for the first time the technique of multiple imputations, it corresponds more to the nature of our data.

\footnotetext{
${ }^{1}$ El Andaloussi, K. Faiq, M. «la situation du préscolaire : importance, diagnostic et concept pédagogique ».

${ }^{2}$ The tests were validated empirically by the internal validity test (Cronbach coefficient).

${ }^{3}$ ECERS (Early Childhood Environnment Rating Scale), This grid used previously as an instrument of accreditation in the United States by the NAYEC (National Association for the Young Children), it is recognized by its empirical validity, and this, thanks to the consistency of measurement and the magnitude of the correlations between the aspects taken into consideration and the final score of the quality.
} 
The multiple imputation method can be described in three steps. The first is to create plausible value groups for the missing data (our case $m=10$ ). Each of these groups of values is used to fill in the missing values and thus create $\mathrm{m}$ databases. Then, the complete bases are analyzed with the multilevel models with constant and random coefficient. Indeed, the hierarchical nature of these data required the use of multilevel modeling. The latter are privileged because they present a solution to all the constraints imposed by ordinary regressions in particular, the non-independence of errors, the heterogeneity of relations, homoscedasticity and the problems of aggregation or disaggregation of hierarchical data (Bressoux, 2008).

\subsection{Results}

In order to identify the determinants of cognitive performance at preschool age, our analysis goes through a process of six estimates in which we tried to feed the models with the relevant variables allowing both a good fit and a better parsimony.

Table I. Estimated key factors of cognitive performance.

\begin{tabular}{|c|c|c|c|c|c|c|}
\hline VARIABLES & Model (01) & Model (02) & Model (03) & Model (04) & Model (05) & Model (06) \\
\hline \multicolumn{7}{|l|}{$\begin{array}{l}\text { Variables of level I } \\
\text { (Child \& Family) : }\end{array}$} \\
\hline $\begin{array}{l}\text { Age of the child }=1 \text {, } \\
\text { More than } 5 \text { years }\end{array}$ & & $\begin{array}{c}6.31214 \\
(5.85717)\end{array}$ & $\begin{array}{c}7.54102 \\
(5.84909)\end{array}$ & $\begin{array}{c}7.62523 \\
(5.81478)\end{array}$ & $7.27121(5.81640)$ & $\begin{array}{c}9.77624 \\
(6.08873)\end{array}$ \\
\hline $\begin{array}{l}\text { Gender of the child }=1 \text {, } \\
\text { Boy }\end{array}$ & & $\begin{array}{c}-16.23541 * * \\
(5.84492)\end{array}$ & $\begin{array}{c}-15.46739 * \\
* \\
(5.00280)\end{array}$ & $\begin{array}{c}-14.77915 * * \\
(5.14497)\end{array}$ & $\begin{array}{c}-14.90869 * * \\
(5.14330)\end{array}$ & $\begin{array}{c}-14.73048 * * \\
(5.56876)\end{array}$ \\
\hline $\begin{array}{l}\text { Siblings size }=1,3 \\
\text { children and plus }\end{array}$ & & $\begin{array}{c}-23.93300 * * \\
(8.39383)\end{array}$ & $\begin{array}{l}-18.33400 * \\
(8.07066)\end{array}$ & $\begin{array}{l}-19.02893 * \\
(8.07253)\end{array}$ & $\begin{array}{l}-19.09750^{*} \\
(8.08847)\end{array}$ & $\begin{array}{c}-18.07213 * \\
(8.35338)\end{array}$ \\
\hline $\begin{array}{l}\text { Education's level of the } \\
\text { mother }=1 \text {, Primary }\end{array}$ & & & $\begin{array}{c}22.08107 * * \\
(8.17134)\end{array}$ & $\begin{array}{l}22.96561 * * \\
(7.98512)\end{array}$ & $\begin{array}{c}23.37366^{* *} \\
(7.95174)\end{array}$ & $\begin{array}{c}23.70437 * * \\
(8.06338)\end{array}$ \\
\hline $\begin{array}{l}\text { Education's level of the } \\
\text { mother = } 1, \text { Middle } \\
\text { school }\end{array}$ & & & $\begin{array}{c}35.75024 * * \\
* \\
(7.71618)\end{array}$ & $\begin{array}{l}34.59275 * * * \\
\quad(7.55107)\end{array}$ & $\begin{array}{l}35.53145 * * * \\
(7.52842)\end{array}$ & $\begin{array}{l}35.97416 * * * \\
\quad(7.17420)\end{array}$ \\
\hline $\begin{array}{l}\text { Education's level of the } \\
\text { mother }=1 \text {, Secondary }\end{array}$ & & & $\begin{array}{c}42.57335^{* *} \\
* \\
(9.39325)\end{array}$ & $\begin{array}{l}40.80688 * * * \\
(9.27691)\end{array}$ & $\begin{array}{l}41.41924 * * * \\
\quad(9.27597)\end{array}$ & $\begin{array}{c}40.08790 * * * \\
(11.19143)\end{array}$ \\
\hline $\begin{array}{l}\text { Education's level of the } \\
\text { mother = } 1, \\
\text { Postsecondary }\end{array}$ & & & $\begin{array}{c}62.82884 * * \\
* \\
(12.11279)\end{array}$ & $\begin{array}{c}59.68642 * * * \\
(11.64979)\end{array}$ & $\begin{array}{c}59.8208 * * * \\
(11.75526)\end{array}$ & $\begin{array}{c}53.52829 * * * \\
(11.17067)\end{array}$ \\
\hline $\begin{array}{l}\text { Education's level of the } \\
\text { father }=1 \text {, Primary }\end{array}$ & & & $\begin{array}{l}-2.17374 \\
(11.90465)\end{array}$ & $\begin{array}{l}-1.38915 \\
(12.01556)\end{array}$ & $-1.95204(12.02375)$ & $\begin{array}{c}-1.55374 \\
(12.80473)\end{array}$ \\
\hline $\begin{array}{l}\text { Education's level of the } \\
\text { father = } 1, \text { Middle } \\
\text { school }\end{array}$ & & & $\begin{array}{c}-3.15752 \\
(11.76608)\end{array}$ & $\begin{array}{c}-2.88607 \\
(11.52837)\end{array}$ & $-3.09310(11.58181)$ & $\begin{array}{c}-2.45182 \\
(11.42832)\end{array}$ \\
\hline $\begin{array}{l}\text { Education's level of the } \\
\text { father }=1 \text {, Secondary }\end{array}$ & & & $\begin{array}{l}12.60540 \\
(10.64344)\end{array}$ & $\begin{array}{c}10.18380 \\
(11.04512)\end{array}$ & $\begin{array}{c}10.22772 \\
(11.08702)\end{array}$ & $\begin{array}{c}10.38644 \\
(11.16800)\end{array}$ \\
\hline $\begin{array}{l}\text { Education's level of the } \\
\text { mother = } 1, \\
\text { Postsecondary }\end{array}$ & & & $\begin{array}{c}35.25402 * * \\
(11.89469)\end{array}$ & $\begin{array}{l}27.80458 * \\
(12.76325)\end{array}$ & $\begin{array}{l}27.60742 * \\
(12.80491)\end{array}$ & $\begin{array}{l}26.53529 * \\
(12.91726)\end{array}$ \\
\hline $\begin{array}{l}\text { Socioprofessional status } \\
\text { of father }=1 \text {, Agr / Art / } \\
\text { Ouv }\end{array}$ & & & & $\begin{array}{c}-8.57951 \\
(12.85466)\end{array}$ & $\begin{array}{c}-8.92849 \\
(12.72700)\end{array}$ & $\begin{array}{c}-9.12544 \\
(12.81981)\end{array}$ \\
\hline $\begin{array}{l}\text { Socioprofessional status } \\
\text { of father = } \\
\text { Empl/CadSup/Chef }\end{array}$ & & & & $\begin{array}{c}4.19036 \\
(16.31574)\end{array}$ & $\begin{array}{c}3.51567 \\
(16.13726)\end{array}$ & $\begin{array}{c}1.47388 \\
(16.05375)\end{array}$ \\
\hline $\begin{array}{l}\text { Family structure }=1, \\
\text { single parent family }\end{array}$ & & & & $\begin{array}{l}-4.51256 \\
(6.52920)\end{array}$ & $\begin{array}{l}-5.00098 \\
(6.64729)\end{array}$ & $\begin{array}{l}-3.87376 \\
(6.75992)\end{array}$ \\
\hline
\end{tabular}




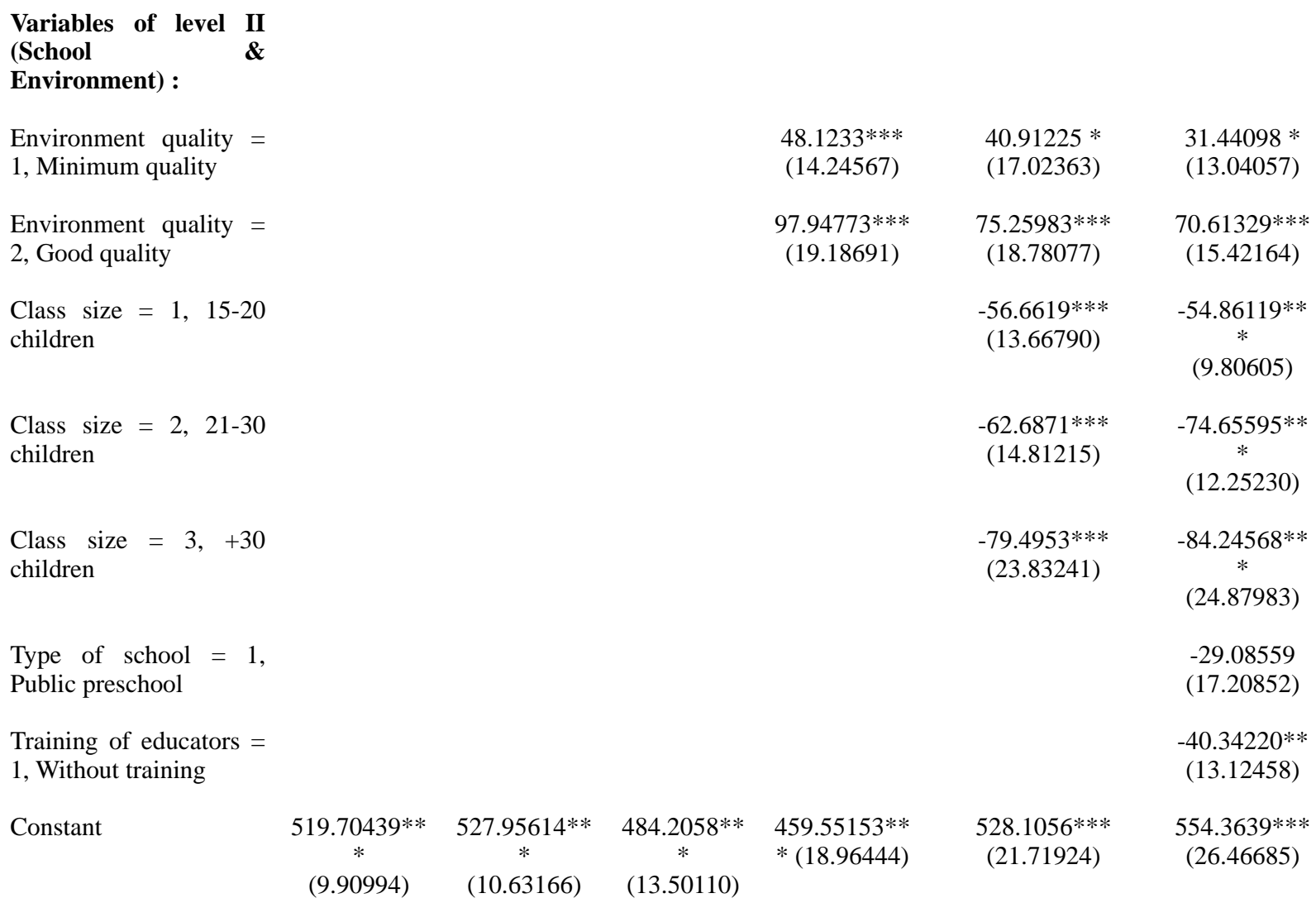

Random-effects :

Level II :

Inter-school

$63.7653 * * * \quad 63.30388 * * *$

$52.7178 * * *$

$40.56989 * * *$

$38.17413 * *$

$37.088 * * *$

variability

(6.817021) (6.887245)

(6.139677)

(5.180853)

(4.784237)

(5.160244)

Slope variability

Mother

with

Postsecond

$31.524 * * *$

(9.861134)

Correlation ary

$\underline{\text { slope-constant }}$

\begin{tabular}{|c|c|c|c|c|c|c|}
\hline $\begin{array}{ll}\text { - } & \text { Corr } \\
\text { (Slope, } \\
\text { Constant) }\end{array}$ & & & & & & $\begin{array}{c}-1 * * * \\
(0.00086)\end{array}$ \\
\hline $\begin{array}{l}\text { Level I : } \\
\text { Intra-school } \\
\text { variability }\end{array}$ & $\begin{array}{l}71.1150 * * * \\
(4.193543)\end{array}$ & $\begin{array}{c}70.06092 * * * \\
(3.972941)\end{array}$ & $\begin{array}{c}66.36915 * * * \\
(4.028722)\end{array}$ & $\begin{array}{c}66.11033 * * * \\
(4.00813)\end{array}$ & $\begin{array}{c}66.09487 * * \\
* \\
(4.012316)\end{array}$ & $\begin{array}{l}65.517 * * * \\
(4.244841)\end{array}$ \\
\hline $\begin{array}{l}\text { Log (Likelhood) } \\
\text { Observations } \\
\text { Number of schools }\end{array}$ & $\begin{array}{c}-139331.17 \\
784 \\
45\end{array}$ & $\begin{array}{c}-130196.35 \\
784 \\
45\end{array}$ & $\begin{array}{c}-125870.9 \\
784 \\
45\end{array}$ & $\begin{array}{c}-125814.77 \\
784 \\
45\end{array}$ & $\begin{array}{c}-125777.11 \\
784 \\
45\end{array}$ & $\begin{array}{c}-123151.7 \\
784 \\
45\end{array}$ \\
\hline
\end{tabular}

Standard errors in parentheses

$* * * \mathrm{p}<0.01, * * \mathrm{p}<0.05, * \mathrm{p}<0.1$

According to the Table I summarizing the estimates made of the cognitive score, the empty model (Model 01 in the table) that does not contain any explanatory variables reflects a simple decomposition of the variance. In fact, the variance is subdivided into one part of inter-school variance and one part of in-school variance.

At this level of analysis (empty or unconditional model), we pay a lot of attention to the intra-school correlation 
coefficient also called "Rho", this coefficient informs us about the proportion of inter-school variance occupied in the variance total. From this, we can have information on the degree of similarity of the cognitive scores of preschooled children within their groups (schools). In the case of the empty model of the total cognitive score,

$$
R h o=\frac{63.7653}{71.1150+63.7653}=0.4728 .
$$

This simply means that $47.28 \%$ of the total variance in the cognitive score of preschool children resides between schools. In other words, the inter-school variance of the total cognitive score occupies $47.28 \%$ in the total variance. Of course, there are schools where cognitive scores are on average higher than in others.

\subsection{Model Building Steps}

In the second model of the Table I, we started introducing explanatory variables. Moreover, we started at first the characteristics properly related to the preschooled child. From this, we try to identify the possible effects of certain specificities properly related to the child, including his age, his gender and the size of his siblings (number of brothers and sisters). That said, we find that the gender of the child is a variable whose impact on the cognitive score is negative and statistically significant. Consequently, the significance of the negative sign of the effect of gender reveals that, on average, the transition from a girl to a boy will lead to a decrease in the cognitive score. In other words, girls are more likely to acquire a higher level of cognitive skills than boys. As for the effect of the number of siblings on the cognitive score, we note that it is also statistically significant and negative. This negativity states in our case that on average when the sibling size exceeds or equal to three it implies a decrease in the total cognitive score. As for the age's variable, we can see that its effect is positive but a priori it is not significant in the second model. Having said that, we kept age's variable in our model all the same because we will see the adjustment of its coefficient as we introduce other explanatory variables.

It should also be noted that in the second model, we infer that the introduction of the variables characterizing the child (age, gender and sibling size) has modified the random component of the previous model (empty model). In other words, the two components of the total variance, namely inter and intra-school variance, have undergone different changes. In fact, we notice that the intra-school variance has been slightly downgraded from 71 to 70 , which means that adding the child's explanatory variables explains some of the variance emanating from the child and his family. As for the inter-school variance, it decreased slightly from 63.76 to 63.30 , at this level of analysis (inter-school variance), it should be noted that sometimes and following the introduction of the variables of level I (child and his family), we can see a slight increase in inter-school variance, this can be explained by the fact that some variables characterizing the child and his family (level I) can vary and interact also at level II (school and its environment) which leads to an increase in inter-school variance. That said, the change in the random component observed by moving from the empty model (model (01)) to model (02) remains very timid, this is obviously due to the non-consideration of other potentially explanatory variables in the second model.

At the third model, to capture the intra-school effect of early childhood, we introduced other variables that characterize the parents, and this, to identify other family dimensions that may further explain the intra-school variance. Indeed, in the model (03) we added variables characterizing the intellectual level of the parents (level of education of the father and the mother). We find in model (03) that the addition of the explanatory variables characterizing parents' educational level further improved the adjustment of the effect of age, gender and number of siblings, and while keeping a statistical significance of the gender and sibling size variable. Regarding the newly introduced variables in the model (03), we note that the effect of the mother's education level is positive and statistically very significant for all categories of this variable (primary, secondary, secondary and postsecondary). While the level of education of the father is significant only after secondary school with a positive impact, moreover, when the level of education of the father goes to primary or secondary school the impact on the cognitive score is negatively very small, as it is said that when its level goes on to secondary or post-secondary school, the impact becomes positive but whether it is the transition to primary, secondary or secondary school, the effects remain statistically insignificant, unlike the post-secondary level, which contributes significantly and positively to cognitive score of the child.

At the level of the fourth model, we proceeded by the introduction of certain variables of level I likely to explain the variability of the cognitive score at the intra-school level in particular, the socio-professional status of the father and the structure of the family (traditional or single-parent) ) and a variable describing level II (school and its environment) reflecting the score of the overall quality of the preschool environment (model (04)), and this, to determine on the one hand the effects strictly related to the quality of the environment. On the other hand, we are also looking for a better specification of the random part of the model. For the socioprofessional status of the father and the family structure (model (04)), we note that the shift from a traditional family to a single parent 
family negatively affects the total cognitive score recorded, but this impact remains statistically insignificant. As for the socio-professional status of the father, we deduce that children with fathers in well-paying positions (senior managers and entrepreneurs) have on average a higher cognitive score compared to other children, but this impact remains statistically no significant. The introduction of these Level I variables and the Preschool Environment Quality Score as a Level II variable greatly improved the specification of the random components, as inter-school variance dropped from 52.7 to 40.50 , accounting for $23 \%$ of the inter-school variance observed in the previous model, this gives a priori idea of the importance of the contribution of environmental quality in improving the cognitive skills of preschool children.

That said, we also find that the addition of the variables reflecting the quality of the preschool environment and the class size (model 05) brought on one side an adjustment to the coefficients (slopes) of the explanatory variables level I (child and his family), moreover a large part of the slopes have been readjusted while keeping a little close the level of significance and the sign of the departure (with also some variables whose level of significance is revised downwards), ditto for the random component and more specifically inter-school variance which has been significantly reduced. We find from both models (models (04) and (05)) that the impact of the quality of the preschool environment is positive (as the quality improves the total cognitive score increases) and statistically significant. As for class size, this variable has a negative and statistically significant impact, which suggests that as class size increases, the cognitive score decreases. On the other hand, the comparison between the random-constant model (model (05)) and the empty model (model 01) shows that the addition of level II variables provided a better specification of the variance, and this, when the latter has significantly changed. Compared to the empty model, the random component has significantly changed for both inter and intra-school variance components. In fact, from the empty model to the 05 model, the intra-school variance has dropped from 71 to 66 , or about $8 \%$ of the explained variance. In other words, variations in the total cognitive score from one child to another in the same school are explained by up to $8 \%$ by gender, age, number of siblings, level of parents' education, and the socio-occupational status of the father and the family structure. Consequently, a very large proportion of intra-school variance remains unexplained despite the use of several variables characterizing the child and his family. With regard to inter-school variance, the latter experienced a drastic drop compared to the empty model, from 64 to 38 , or $41 \%$ of the explained variance. This significant decrease in variance is explained by the good diet and adjustment of the random effects model.

In order to bring a better fit of the final model and to improve the specification of its random component, we asked ourselves the question of a possible heterogeneity of impact between some Level I variables and the cognitive score (in our case, we chose examine the heterogeneity of a post-secondary mother's impact on the total cognitive score). This amounts to assuming that for example the relationship between the mother's (post-secondary) education level and the total cognitive score is not the same from one school to another, implicitly means that the regression lines do not have the same slope and therefore are not parallel. It is this reason that led us to specify a random effect of the relationship between the post-secondary education level of the mother and the total cognitive score (see Appendix). In other words, in model 06, we allowed that the coefficients (slopes) of the regression lines vary randomly from one school to another. Consequently, we will also have to estimate the variance of these coefficients and their covariance with the constants that are already random.

One of the major spans that can be noticed in the random slope model (model 06) is that it allows a significant adjustment of the data compared to previous models. Moreover, the effects of certain variables improved in terms of statistical significance, namely the quality of the preschool environment and the child's sibling size. Other newly added variables have been found to be significant, namely, the regular training of educators. To confirm the improvement of the fit of the model, we must use the deviance that raises the relevance of the model 06 compared to previous models that contain fewer explanatory variables or are less complicated (random constant model vs. random slope model). Before looking at the interpretations and discussion of the results of the final model (model 06), we stopped at the level of the tests making it possible to judge the validity and the relevance of this model, and this, through the analysis of the explanatory potential and the deviance (other tests can be found in the appendix).

\subsection{Validity of the Final Model}

To make a judgment on the magnitude of the variance explained by this final model (model 06) we will call upon the calculation of the explanatory power of this model that we commonly call the "Pseudo $\mathrm{R}^{2 \text { ", indeed, the }}$ explanatory power of the model with constants and random slopes can be deduced from the same principle of the coefficient of determination calculated in ordinary least squares (OLS). It is also calculated for each hierarchical level by simply taking the difference of the variance of the empty model and the residual variance related to the 
variance of the empty model. Other authors suggest the removal of random coefficients before the calculation of the explanatory power, and this, because this process will generate values closer to the correct version (Snijders and Bosker 1999).

According to the table summarizing the set of multilevel models of the cognitive score, we have the total estimated variance of the empty model (model 01):

$$
\hat{\varphi}_{0}+\hat{\theta}_{0}=63.7653^{2}+71.1150^{2}=9123.35671
$$

While the total estimated variance in the final model (model 06) is:

$$
\hat{\varphi}_{F}+\widehat{\theta}_{F}=37.088^{2}+65.517^{2}=5667.9971
$$

From where:

$$
\text { Pseudo } \boldsymbol{R}^{2}=\frac{\left[\left(\hat{\varphi}_{0}+\hat{\theta}_{0}\right)-\left(\hat{\varphi}_{F}+\hat{\theta}_{F}\right)\right]}{\hat{\varphi}_{0}+\hat{\theta}_{0}}=\frac{9123.35671-5667.9971}{9123.35671}=\mathbf{0 . 3 7 8 7 3 7 7 6}
$$

This means that the explanatory variables level I and II that were added to the final model of the total cognitive score (model 06) could explain 38\% of the total variance. As already indicated, this explanatory power of the model can be broken down into two parts, and this, by calculating also the explanatory power for each level (Raudenbush and Bryk 2002). In this sense, we will try to calculate the proportional reduction in each component of the total variance, between the empty model (model 01) and the final model (model 06).

Indeed, the explained proportion of the variance of level II (school and its environment) by the explanatory variables is $66 \%$ :

$$
\text { Pseudo } R_{2}^{2}=\frac{\left[\left(\hat{\varphi}_{0}-\hat{\varphi}_{F}\right)\right]}{\hat{\varphi}_{0}}=\frac{63.7653^{2}-37.088^{2}}{63.7653^{2}}=\mathbf{0 . 6 6 1 7 0 3 1}
$$

The explained proportion of the variance of level I (child and family) by the explanatory variables is $15 \%$ :

$$
\text { Pseudo } \boldsymbol{R}_{1}^{2}=\frac{\left[\left(\hat{\theta}_{0}-\hat{\theta}_{F}\right)\right]}{\hat{\theta}_{0}}=\frac{71.1150^{2}-65.517^{2}}{71.1150^{2}}=\mathbf{0 . 1 5 1 2 3 8 6 8}
$$

We can also analyze the change in total variance from model 05 to final model (model 06). It should be noted that the authorization of the slope of the variable level of education of the mother (post-secondary level) has, on the one hand, led to an increase in inter-school variance, which can be explained by the addition of an additional variation which is that of the slopes. On the other hand, this has allowed a reduction in intra-school variance.

\section{The deviance of the final model}

As already indicated, deviance allows us to estimate the relevance of one model over another (usually the upstream model that contains fewer parameters to estimate). For this, the deviance uses the difference between the likelihoods of the two models.

If L5 and L6 are respectively the likelihood of the models 05 and 06, as already indicated the model 06 is the model containing more complexity, and this, because this model allows the variance to the constants and the slopes, the deviance $\mathrm{D}$ is defined as following:

$$
D=-2\left(\log L_{5}-\log L_{6}\right)
$$

Comparing the value of $\mathrm{D}$ with the fractal of the law of $\chi^{2}(\mathrm{~m})$, we reject or reject the hypothesis of the relevance of opting for a model with constants and random slopes compared to the model 05 which refers to the model random constant only. In other words, if the decrease of the deviance is significant between the two models compared (05 and 06), one will retain the one which is more complicated or which understands the additional parameters to estimate (model 06).

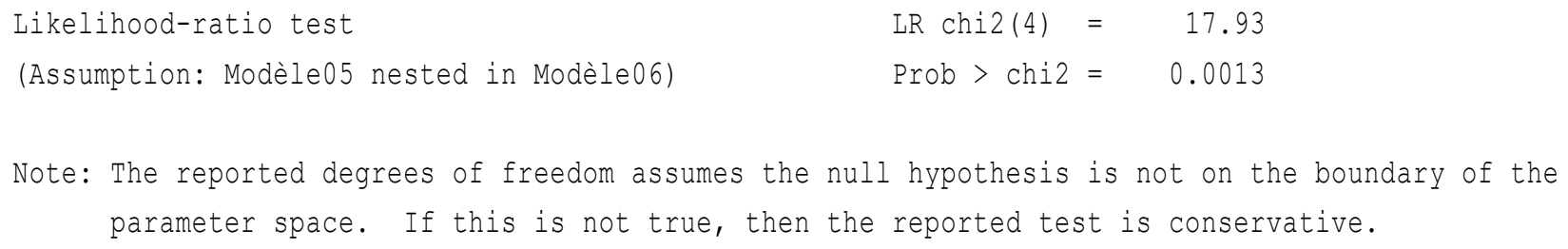

According to this test, at the level of $5 \%$ and a degree of freedom of 4 and a p-value $=0.0013$. We can largely reject 
the null hypothesis that the authorization of slope variability will not provide an explanation for the total cognitive score. That said, it can be concluded that the decrease in deviance is very significant ( $\mathrm{p}$-value $=0.0013$ ) between the two models compared (random-constant model and constant and random-slope model). Consequently, we will retain the most complicated model in which the constants and the slopes are random (model 06).

\section{Results' Discussion}

To illustrate a better visibility of the results obtained in the final estimate, we will proceed with an interpretation of the final model by level.

\subsection{Child \& Family's Level}

The gender of the child plays a decisive role in improving the cognitive score, moreover the transition from a girl to a boy reduces significantly the cognitive score by 15 points, all things being equal. This means that sketches of learning disparities between girls and boys appear before primary school age. This result reflecting the impact of gender is also found by Haveman, Wolf and Spaulding (1991), except that they found a positive but not significant impact. Also the fact that the preschooled child has a sibling size that exceeds 2 members decreases the cognitive score by 18 points. This negative impact of size on performance can be explained by the direct link between family size and the amount of economic resources allocated to children (Arleen Leibowitz 1974, Wolf and Haveman 1995). However, it should be noted that this variable is only significant in our results at $10 \%$. As a result, in preschool age our results do not support the favorable position for the significant link between family size and cognitive skills.

Compared to a Child with an illiterate mother, their peers, whose mother has a level of education of elementary, middle, and secondary have a score higher on average by 24 points, 36 points and 40 points, respectively. By contrast to the level of education of the father that does not have a statistically significant impact on cognitive learning, and this, excluding post-secondary where the incidence becomes insignificant (at the $10 \%$ threshold). With this post secondary level of the father, the children review their preschool performances 27 points up higher (ceteris paribus). This is tantamount to saying that the education of the mothers of preschool children is very decisive in terms of preschool learning for all levels. However, fathers' level of education contributes to cognitive learning only after secondary school. This result is also found by Ribar (1993) and Datcher (1982), both concluding in their studies that the mother's human capital is more critical than that of the father in terms of skill acquisition and success. Our results also reveal that as parents' level of education increases, the impact on the cognitive score increases and peaks at the postsecondary level of parents. In the empirical literature, this finding is also shared in several studies (Haveman, Wolf and Spaulding 1991, Behrman 1991). Indeed, these studies have all confirmed that a year or two in post-secondary education has the greatest impact on the skills acquired and consequently on the success of children.

It should also be noted that the results revealed that the father's socio-professional status and the family structure (traditional / single-parent family) of children at an early age do not have a significant impact on the preschool performances of these children. The results concerning the non-contribution of socioprofessional status to cognitive acquisitions are consistent with the results found by Cherkaoui (1999) and Duru-Belat (2003). Indeed, these studies have confirmed that despite the particularly difficult socio-economic conditions, some children from disadvantaged backgrounds manage to record important results. In other words, being part of any social category will not systematically result in a predefined outcome at preschool age.

As for the family structure, unlike a majority of studies that have confirmed the significant impact of family structure (Ribar 1993, Manski et al 1992, Haveman et al 1991), our results reveal that there is no significant influence of this variable on children's preschool performance. Although this observation does not align with the majority of studies, Wolf and his associates (1995) come close to our results, and this, by qualifying the influence of the family structure on the children's success by a "weak influence". Regarding the age of children in the preschool level, the results obtained from the final model stipulate that beyond 5 years, children improve their cognitive performance by about 10 points, all other things being equal. However, this impact remains statistically insignificant.

\subsection{School \& Environment's Level}

The second level, which focuses on the school and its environment, only variables related to the quality of preschool environment, training of teachers and class-size that revealed a statistically significant effect on cognitive learning. Indeed, when the multidimensional quality of the preschool environment changes from "inadequate" quality to "minimal" quality, cognitive performance improves by 32 points. While once the threshold of "good" quality is reached, cognitive performance increases significantly by 71 points, all things 
being equal. As a result, children in an "Inadequate" quality learning environment are likely to acquire less cognitive skills compared to children in "Good" and "Excellent" quality environments. This leads to the conclusion that the quality of the environment significantly favors the development of early childhood in general and cognitive skills in particular. Our results align with all recent studies that have concluded the importance of environmental quality as a key determinant in the learning of preschool skills (François and Poupeau, 2008 ; Grisay 2007 ; Duru-Bellat, 2003 ; Meuret 2000 ; Mingat, 1984).

Moreover, teachers who have benefited from regular preschool training, raise students' average score by 41 points compared to their peers who are taught by untrained. Consequently, teachers who have benefited from regular training in preschool makes his children progress better than teachers who practiced without any special training in preschool. In other words, the regular training of teachers makes it possible to promote learning in preschool education. These findings confirm the results of several studies (Meuret, 2000, Duru-Bellat 2003, Grisay, 1997) sharing the training of educators as an element having an effect on the cognitive abilities of early childhood.

However, it should be noted that the variables describing the experience, the academic level of the educators and the follow-up of the homework and activities have been removed from the model, for the little that they bring to the explanation of the children's results. Indeed, whether it is the academic level of the educators or the accumulated experience of the educators, the results revealed that there is no relation between these two variables and the cognitive performances acquired at the preschool age. These findings echo the same conclusions of some researchers (Rivkin, Hanushek and Kain, 2005) and go against some others (Duru-Bellat, 2003 ; Meuret, 2000 ; Grisay, 1997 ; Cherkaoui, 1999 ; Psacharopoulos and Woodhall, 1988).

As for the number of children per group (class size), it should be noted that in the preschool cycle, the highest class size leads to the weakest cognitive results, and the smallest size leads to the highest cognitive performance. In fact, children whose group size is less than 15 children per group improve their total cognitive score by 55 points compared to those whose number is between 15-20. They (fewer than 15 children) further improve their total cognitive score by 75 points compared to children between 21-30 children per group. Also, they (fewer than 15 children) further improve their total cognitive score by 85 points compared to children whose enrollment exceeds 30 children per group. This leads to the conclusion that the smaller the group size, the less children learn. These results are consistent with the findings of many studies (Rivkin and al, 2005, Leroy-Audouin and Mingat, 1995, Blatchford et al, 2004, Leroy-Audouin, 1995). Regarding the impact of the type of preschool (public / private) on the cognitive score, our results reveal that the transition from a public preschool to a private preschool results in a total cognitive performance increase by 30 points. Nevertheless, the impact of preschool type was not statistically significant.

After discussing the results from the interpretation of the fixed coefficients of the final estimate, it is worth noting that the introduction of the random effect on the impact of mothers with postsecondary education has led to a change in the inter-school variance. In fact, the inter-school variance of the cognitive score varies according not only to the measurement of the total cognitive score but also to the scale of measurement of the variables whose slopes are random. As a result, inter-school variance becomes more complicated by having a quadratic function of these variables. Also, we must be very careful with respect to their interpretation and this because the scales of the variance and the covariance do not remain the same. As a result, it is not logical to compare the magnitude of the variance of the random constants and the variance of the random coefficients (Rabe-Eesketh, Skrondal, Edition:3) ${ }^{4}$. To interpret the estimate of standard deviations of random constants and coefficients, the literature recommends the construction of intervals that contain $95 \%$ of schools.

For the random slopes of children whose education level of mothers is at postsecondary level, the interval will be:

$$
\begin{gathered}
{\left[\hat{\beta}_{2}-1.96 . \sqrt{\operatorname{Var}\left(\hat{\delta}_{2 j}\right)} ; \hat{\beta}_{2}+1.96 . \sqrt{\operatorname{Var}\left(\hat{\delta}_{2 j}\right)}\right]} \\
{\left[53.52829-\left(1.96 * \sqrt{31.524^{2}}\right) ; 53.52829+\left(1.96 * \sqrt{31.524^{2}}\right)\right]} \\
{[-8.25875 ; 115.31533]}
\end{gathered}
$$

\footnotetext{
${ }^{4}$ Rabe-Eesketh, S. Skrondal, A. «Multilevel and Longitudinal Modeling Using Stata , Volume I «Continuous Responses », Edition $\mathrm{N}^{\circ} 3$.
} 
This implies that $95 \%$ of schools have slopes for the mother's postsecondary variable that range from -8.26 to 115.32 points. As we can see, the postsecondary post-secondary coefficient range is broad enough for a possible crossover of school regression lines (see Appendix).

For random constant:

$$
\begin{gathered}
{\left[\hat{\beta}_{1}-1.96 . \sqrt{\operatorname{Var}\left(\hat{\delta}_{1 j}\right)} ; \hat{\beta}_{1}+1.96 . \sqrt{\operatorname{Var}\left(\hat{\delta}_{1 j}\right)}\right]} \\
{\left[554.3639-\left(1.96 * \sqrt{37.088^{2}}\right) ; 554.3639+\left(1.96 * \sqrt{37.088^{2}}\right)\right]}
\end{gathered}
$$

[481.67; 627.06]

Therefore, we can conclude that $95 \%$ of schools have their constant between 481.67 and 627.06 points. In other words, the total cognitive score of schools varies on average between 481.67 and 627.06 points.

\subsection{Conclusion}

The purpose of this work was to decorticate and analyze the determinants of cognitive learning quality in Moroccan preschool. For this, we used the data from a study that covered more than 780 children in the final year of the preschool cycle. These children are spread over 45 schools. The results of the different multilevel models elaborated in this research reveal that the cognitive performance during preschool does not only depend on the characteristics relating to children and their families but also on the specificities characterizing the school environment, the educators in charge and the quality of services offered in early childhood. Thus, we were able to answer the central question of our research, which questioned the key factors in cognitive performance learning in preschool age.

Indeed, concerning parents' education, our results reveal that cognitive learning in early childhood is not very sensitive to the father's eduction, the latter only becomes a determinant once the level of his education exceeds the secondary (post-secondary) level. However, it is clear that as the level of education of the mother evolves, early childhood significantly improves their cognitive performance. This amounts to concluding that the mothers' education is more decisive in cognitive learning at an early age. Similarly, our results reveal that belonging to any socio-professional category will not influence the skills acquired in preschool education. With regard to sibling size, our results reveal that, in fact, a child with a sibling size exceeding two members reduces these cognitive performances. However, it should be noted that this negative influence is only statistically significant in our results at the $10 \%$ threshold. As for the structure of the family, we find that there is no significant influence of this variable on the preschool performance of children. In other words, whether the children belong to a single-parent or traditional family, children's cognitive outcomes remains insensitive to this variation.

Other factors also contribute to the explanation of cognitive performances acquired in preschool especially, the preschool environment. To identify the effects of school that may influence preschool learning, we used some explanatory variables. For example, the preschool environment quality score, the results reveal that this variable plays a key role in preschool learning, as it has a positive and statistically significant effect. In fact, as the quality of the environment improves, children improve their cognitive performance even more. As a result, children in a quality learning environment called "Inadequate" are likely to acquire less cognitive skills compared to children in "Good" quality settings. This leads to the conclusion that the quality of the environment significantly favors the development of early childhood in general and cognitive skills in particular. As for the class size or the number of children per group (class), it should be noted that in the preschool cycle, the highest class size leads to the weakest cognitive results, and the smallest size leads to the highest cognitive performance. Similarly, for the training of preschool teachers, our results show that children with a teacher who has benefited from regular training had significantly higher cognitive performance than children whose teachers are untrained. Hence, the important role of teacher's training enabling them to promote preschool learning. On the other hand and according to our results, it is advisable to point out that the academic level or the accumulated experiences by teachers have no impact on the cognitive performances acquired at the preschool age.

By limiting ourselves to the results of this research, we can make the following recommendations:

$\checkmark$ First, for the teachers' training, we observed that educators who received training were significantly more effective than untrained teachers. It is therefore necessary to encourage formal and regular teachers' training.

$\checkmark$ Moreover, concerning the environment quality we noted that, in a context that favors the physical, emotional, social and cognitive development of early childhood, this environment manages to produce 
better results than those who do not (inadequate quality). Consequently, it is necessary to introduce standard policies and requirements to ensure the respect of the environment's quality.

$\checkmark$ Also in the preschool cycle, we noticed that high class size leads to poor cognitive outcomes. The results revealed that the best performing class size is one with fewer than fifteen children. It is therefore wise to ensure that the class size does not exceed this size.

\section{References}

Baudelot, C., \& Establet, R. (1971). L'école capitaliste en France, Paris, F. Maspero.

Beck, L. G., \& Murphy, J. (1998). Site-based management and school success: untangling the variables. School Effectiveness and School Improvement, 9(4), 358-385. https://doi.org/10.1080/0924345980090402

BECKER, G. S., \& TOMES, N. (1979). An Equilibrium Theory of the Distribution of Income and Intergenerational Mobility. Journal of Political Economy, 87(6), 1153-1189. https://doi.org/10.1086/260831

Behrman, J. R. (1991). Investing in female education for development.

Blatchford, P., Bassett, P., Brown, P., Martin, C., \& Russell, A. (2004). Effects of Class Size on Attainment and Classroom Processes in English Primary Schools (Years 4 to 6) 2000-2003: Research Brief.

Bourdieu, P., et \& Passeron, J. C. (1964). Les héritiers : les etudiants et la culture, Paris, edition. Minuit, page 189.

Bressoux, P. (1995). Les effets du contexte scolaire sur les acquisitions des élèves : effet-école et effets classes en lecture. Revue française de sociologie, 2, 273-294. https://doi.org/10.2307/3322249

Bressoux, P. (2006). Histoire et perspective des recherches sur l'effet-maître, Recherche sur l'évaluation en éducation, Paris, L'Harmattan, 2006.

Bressoux, P. (2008), Modélisation statistique appliquée aux sciences sociales, Bruxelles : De Boeck.

Cherkaoui, M. (1999). Sociologie de l'education, Paris, 7e edition PUF.

Cousin, O. (1993). L'effet établissement. Construction d'une problématique, Revue française de sociologie, 34-3. pp. 395- 419.

Cousin, O. (1998). De l'institution à l'établissement. Le cas des collèges de banlieue. L'Orientation scolaire et professionnelle, 27(2), 303-325.

Datcher, L. (1982). Effects of community and family background on achievement. The review of Economics and Statistics, 32-41. https://doi.org/10.2307/1937940

Duru-Bellat, M. (2003). Inégalités sociales à l'école et politiques éducatives, UNESCO.

Duru-Bellat, M., \& Mingat, A. (1997). La constitution de classes de niveau dans les collèges; les effets pervers d'une pratique à visée égalisatrice, Revue française de sociologie, 759-789. https://doi.org/10.2307/3322627

El Andaloussi, K. Faiq, M. la situation du préscolaire : importance, diagnostic et concept pédagogique.

François, J. C., \& Poupeau, F. (2008). Les déterminants socio-spatiaux du placement scolaire, Essai de modélisation statistique appliquée aux collèges parisiens. Revue française de sociologie, 49, 93-126. https://doi.org/10.3917/rfs.491.0093

Global Education and Formation. (2014). Diagnostic et Evaluation de l'Etat Actuel du Préscolaire.

GRAS, A. (1974). Z 'Sociologie de l'education : les textes fondamentaux, Paris, Larousse.

Grisay, A. (1997). Evolution des acquis cognitifs et socio-affectifs des élèves au cours des années de collège, MEN-Direction de l'Evaluation et de la Prospective, Dossiers Education et formations, n ${ }^{\circ} 88$.

Grisay, A. (2007), Réflexions sur l'effet école, in Recherche sur l'évaluation en éducation, L'Harmattan, Paris.

Hanushek, E. (1971). Teacher characteristics and gains in student achievement: Estimation using micro data. The American Economic Review, 61(2), 280-288.

Haveman, R., Wolfe, B., \& Spaulding, J. (1991). Childhood events and circumstances influencing high school completion. Demography, 28(1), 133-157. https://doi.org/10.2307/2061340

Jarlégan, A. (2008). Maître-élèves (Interactions). Le dictionnaire des inégalités en France. Paris: ESF, 201-203.

Kerckoff, A. (1986). Effects of ability grouping in british secondary schools. American sociological review, 51, 842-858. https://doi.org/10.2307/2095371 
Lautier, N., \& Allieu-Mary, N. (2008). La didactique de l'histoire, Revue française de pédagogie. Recherches en éducation, 162, 95-131.

Leibowitz, A. (1974). Home investments in children. Journal of Political Economy, 82(2, Part 2), S111-S131. https://doi.org/10.1086/260295

Leroy-Audouin, C. (1995). Les modes de groupement des élèves à l'école primaire, catalyseurs des performances, Cahier de l'Iredu , 95009, Dijon, IREDU.

Leroy-Audouin, C., \& Mingat, A. (1995). L'école primaire rurale en France: structure des classes, efficacité pédagogique et intégration au collège, Rapport pour la direction de la prévision, Ministère de l'économie.

Manski, C. F., Sandefur, G. D., McLanahan, S., \& Powers, D. (1992). Alternative estimates of the effect of family structure during adolescence on high school graduation. Journal of the American Statistical Association, 87(417), 25-37. https://doi.org/10.1080/01621459.1992.10475171

Meuret, D. (2000). Les recherches sur l'efficacité et l'équité des établissements scolaires, leçons pour l'inspection, Université de Bourgogne - IREDU.

Mingat, A. (1984). Les acquisitions scolaires de l'élève au CP: les origines des différences? Revue française de pédagogie, 69(1), 49-63. https://doi.org/10.3406/rfp.1984.1559

Psacharopoulos, G., \& Woodhall, M. (1988). L'éducation pour le développement: une analyse des choix d'investissement, Economica. International Bank for Reconstruction and Development.

Rabe-Eesketh, S., \& Skrondal, A. (2012). Multilevel and Longitudinal Modeling Using Stata, Volume I «Continuous Responses », Edition n³.

Raudenbush, S. W., \& Bryk, A. S. (2002). Hierarchical linear models: Applications and data analysis methods (Vol. 1). Sage.

Ribar, D. C. (1993). A multinomial logit analysis of teenage fertility and high school completion. Economics of Education Review, 12, 153-153. https://doi.org/10.1016/0272-7757(93)90026-D

Rivkin, S. G., Hanushek, E. A., \& KAIN, J. F. (2005). Teachers,Schools And Academic Achievement. Econometrical, 73(2), 417-458. https://doi.org/10.1111/j.1468-0262.2005.00584.x

Robin, J. M. (2009). Qu'est-ce qu'un bon professeur ? Regards de personnels de direction.

Rubin, D. B. (1987). Multiple imputation for nonresponse in surveys, Wiley Series in probability and statistics.

Snijders, T., \& Bosker, R. (1999). Multilevel analysis: An introduction to basic and advanced multilevel modeling, Washington : SAGE.

Veldman, D. J., \& Brophy, J. E. (1974). Measuring teacher effects on pupil achievement. Journal of Educational Psychology, 66(3), 319. https://doi.org/10.1037/h0036500

Wolf, B. L., \& Haveman, R. (1995). The determinants of children attainements: a review of methods and findings, Journal of economic literature. 


\section{Appendix}

Tests of the inter-school variance

i. Likelhood ratio test
Likelihood-ratio test
$\operatorname{LR} \operatorname{chi2}(1)=356.16$
(Assumption: . nested in ri)
Prob $>$ chi2 $=0.0000$

ii. Score test

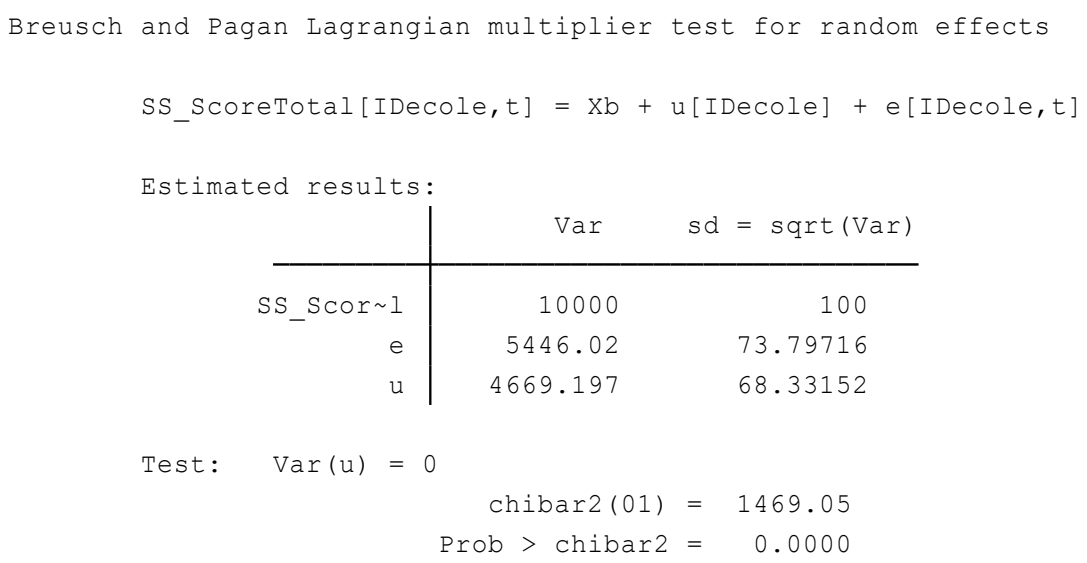

iii. Fisher test

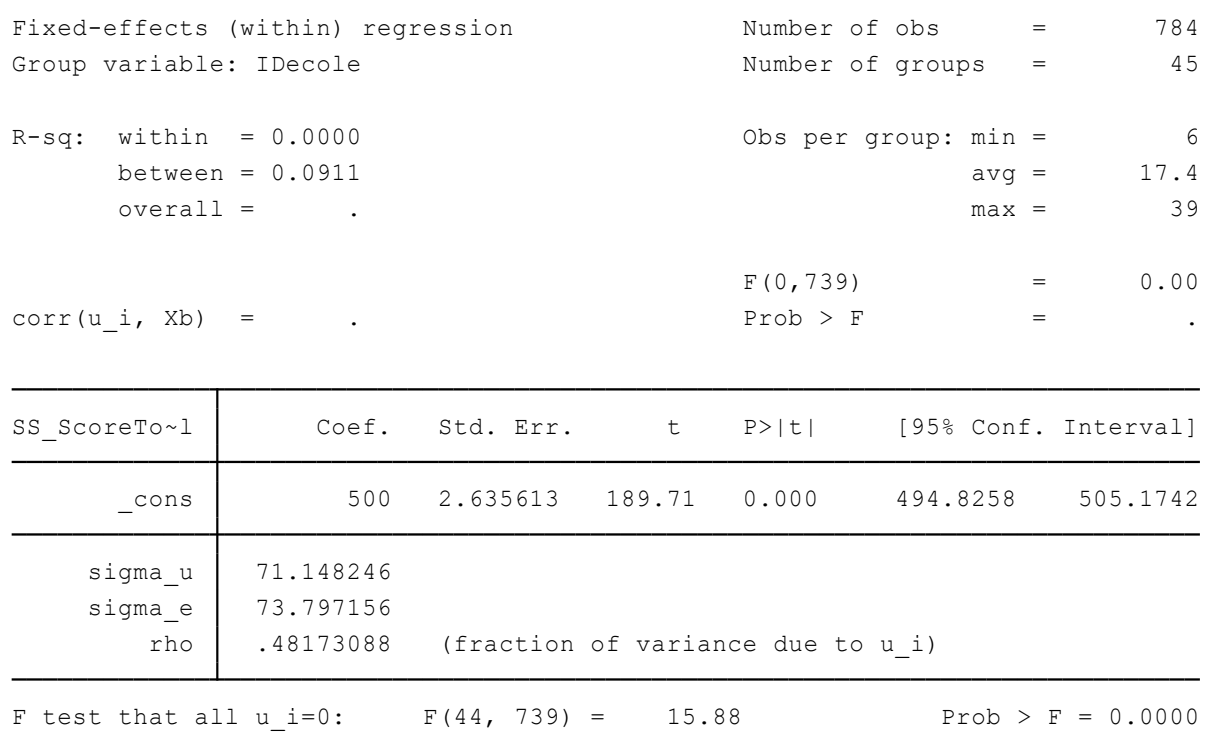




\section{Fixed effect versus Random effect model}

i.

Hausman test

- hausman fixed random

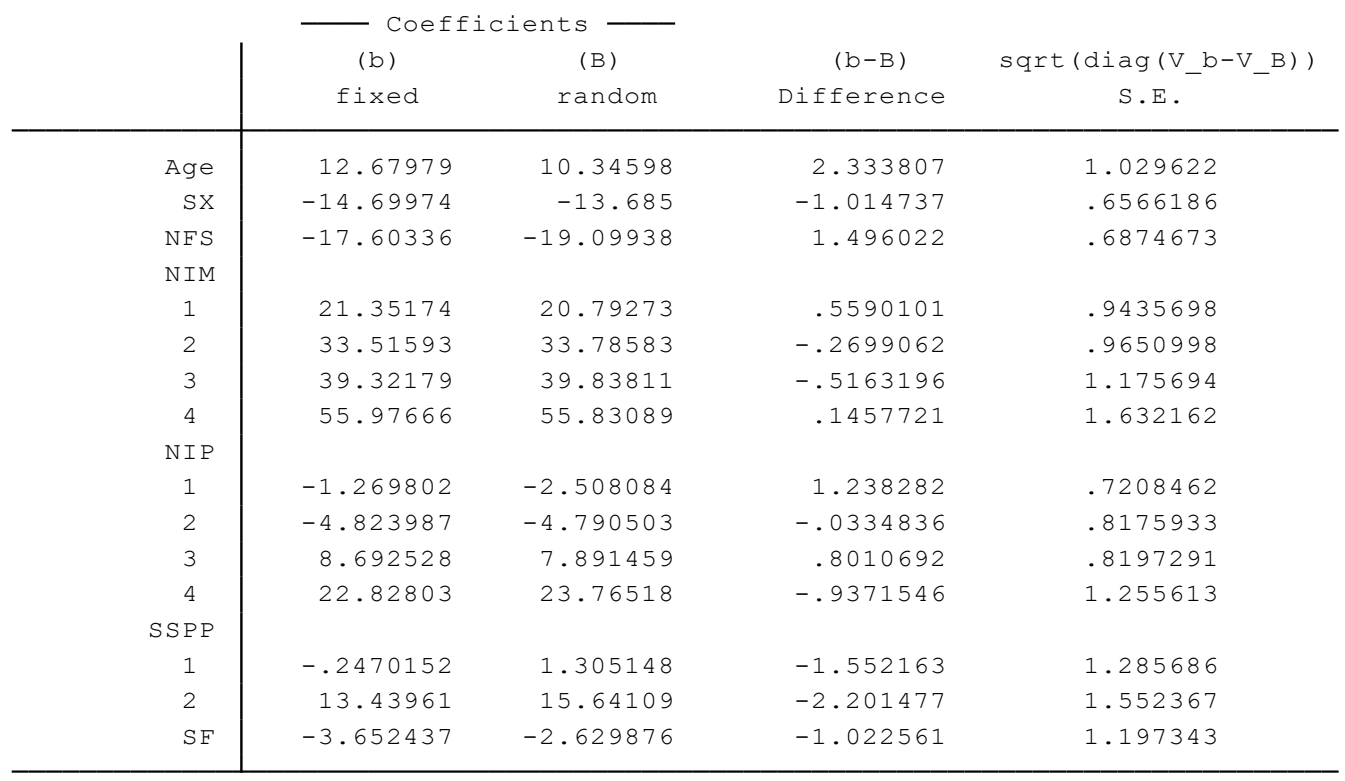

$\mathrm{b}=$ consistent under $\mathrm{HO}$ and $\mathrm{Ha}$; obtained from xtreg

$\mathrm{B}=$ inconsistent under $\mathrm{Ha}$, efficient under Ho; obtained from xtreg

Test: Ho: difference in coefficients not systematic

$$
\begin{aligned}
\operatorname{chi2}(14)= & (\mathrm{b}-\mathrm{B}) \cdot\left[\left(V_{-} \mathrm{b}_{-}-\mathrm{V}_{-} \mathrm{B}\right) \wedge(-1)\right](\mathrm{b}-\mathrm{B}) \\
= & 19.93
\end{aligned}
$$

\section{The level postsecondary of the mother and his heterogeneous impact on the cognitive score}

i. $\quad$ For each and all school

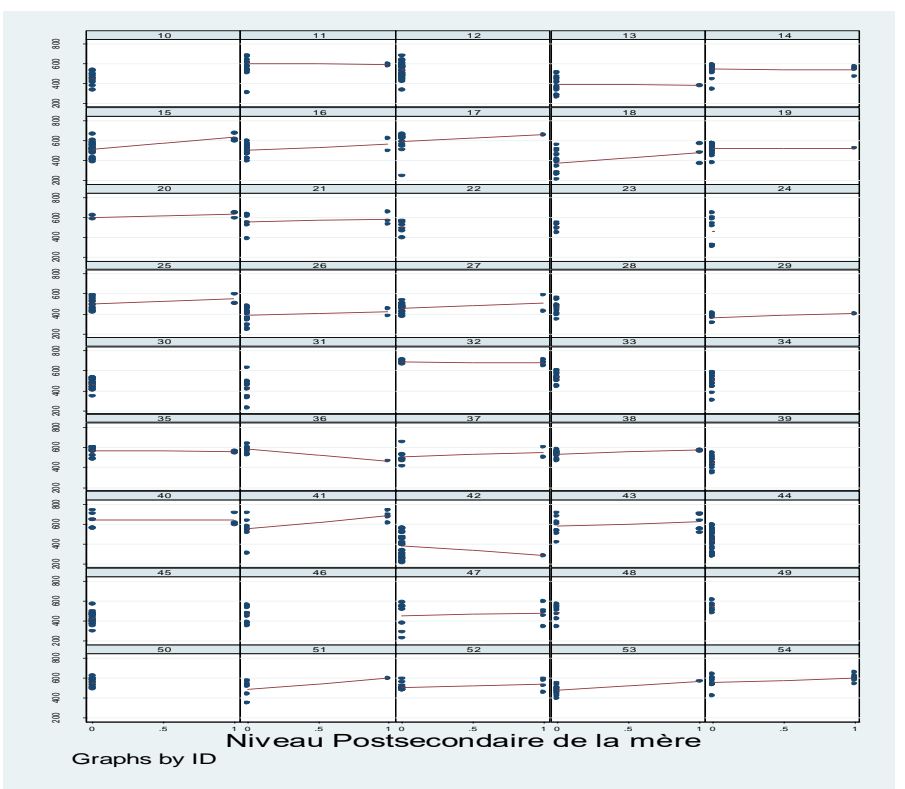




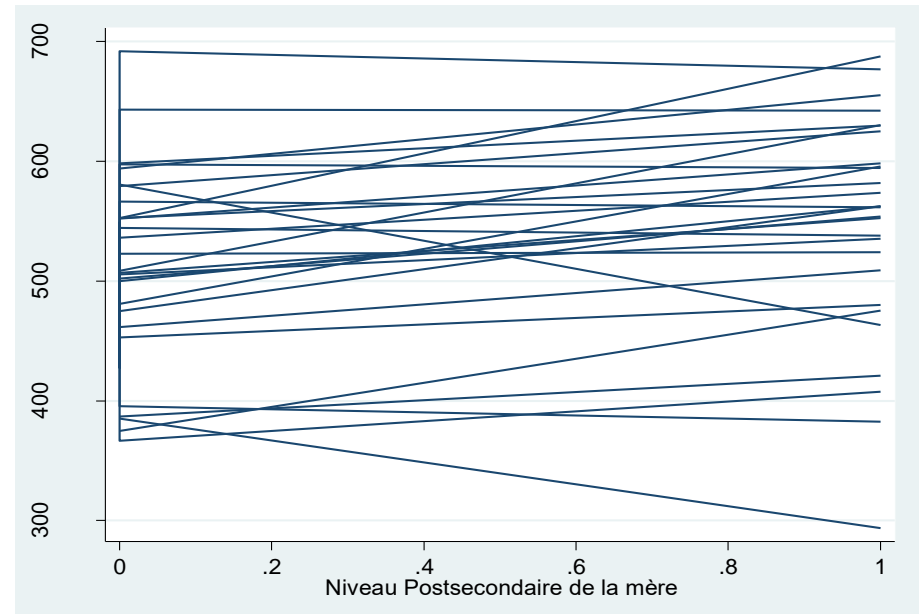

ii. Relationship between constant and random slope

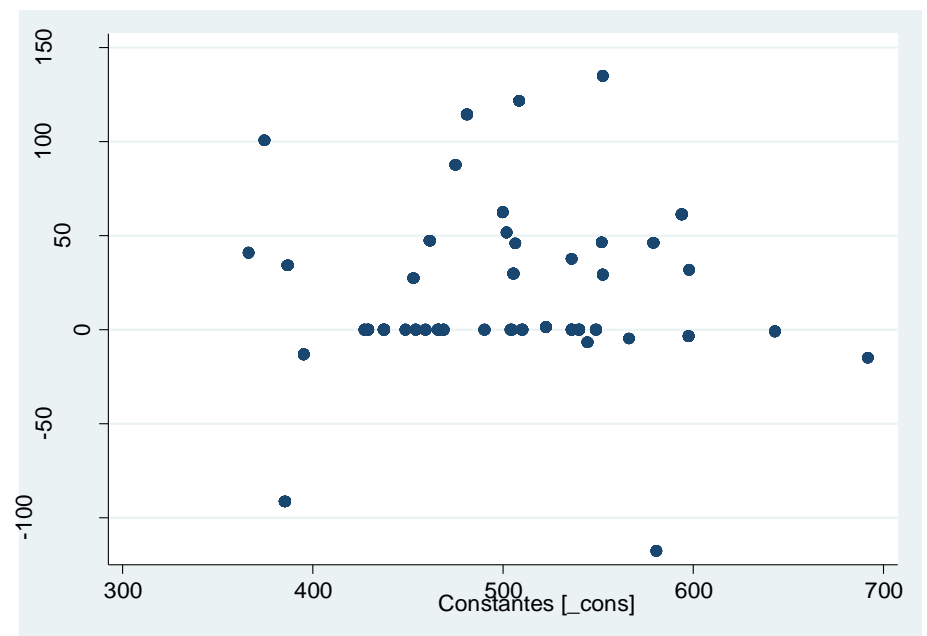

\section{Copyrights}

Copyright for this article is retained by the author(s), with first publication rights granted to the journal.

This is an open-access article distributed under the terms and conditions of the Creative Commons Attribution license (http://creativecommons.org/licenses/by/4.0/). 